\title{
Minimally Invasive Advance Beautification Rhinoplasty
}

\author{
Dr Munir Alam \\ Associate Professor \& HOD Plastic Surgery, Independent Medical College, Faisalabad, Pakistan \\ Consultant Plastic Surgeon, Faisal Hospital, Faisalabad, Pakistan
}

Correspondence author: Dr Munir Alam; mrmuniralam@gmail.com

Received 13 November 2019;

Accepted 29 November 2019;

Published 07 December 2019

\begin{abstract}
Background: Rhinoplasty is the most challenging surgical procedure amongst all the aesthetic/cosmetic operations. As for the challenges with rhinoplasty are great, so the need of minimal invasive techniques, less scarring, quick recovery especially in the asian nose with thick sebaceous nasal tip skin. The aim in beautification rhinoplasty is to improve the aesthetic proportions, volumes, and angles of the nose, adapted to the face as a whole. Frequently the patient desire is to achieve symmetrical, smaller, more attractive nose with better respiration, which require the identification of aesthetic and functional problems to execute the planned operation. Study Period: The author have had performed fifty seven rhinoplasty procedures from July 2014 to July 2017 with almost 6 months follow up period. Material and Methods: The techniques used for almost all rhinoplasty procedures includes T-excision, humpectomy, macidonian technique for lateral digital osteotomy, columellar sliding and nasal tip refinement. Where needed combined with septoplasty, turbinectomy, polypectomy etc additional procedure in nine patients out of fifity seven. Serdev Sutures ${ }^{\circledR}$ in rhinoplasty include: tip rotation, refinement / narrowing of the tip, lower and medial thirds, alar base narrowing and nasal dorsum lifting of concavities and irregularities. Results: With the advancement in minimal invasive techniques, it has become possible to achieve excellent satisfactory results ( $80-100 \%$ by using visual analogue scoring system), where indicated combined with ENT Surgery. Conclusion: The correct nose proportions, angles, and volumes guides the appropriate procedure to the surgeon. By using advance minimal invasive techniques provide predictable results for close rhinoplasty, nearly normal "nonoperated appearance" after atraumatic mini-invasive surgery.
\end{abstract}

Keywords: Cosmetic, Rhinoplasty, Aesthetic, Advance.

\section{Introduction}

Nose is a most prominent part of the face. It is important to be familiar with nasal anatomy and more importantly functional anatomy of the nose. When considering rhinoplasty, three layers of the nose taken into account; external skin and soft tissue, underlying bone and cartilaginous framework and internal mucosal lining of the nose. The thickness of the skin is variable over the nose; thicker in our expereince of asian nose especially around the nasal tip ${ }^{[1]}$.

The detail history of the potential client seeking rhinoplasty should include the patient's expectation level ${ }^{[2,3]}$. While examining the nose, the whole face should be taken into account for correct aesthetic angles, proportion and volumes ${ }^{[4]}$. Any history of breathing difficulty, previous trauma or surgery to the nose should entail complete intranasal examination, ENT surgeon involved if indicated.

In recent years, the trend is more toward minimally invasive techniques in all the surgical fields ${ }^{[4]}$. Most of the cosmetic rhinoplasty procedures are performed as close rather than open technique with minimal invasive surgical and non surgical procedures $^{[4]}$. In the author experience, almost all of the rhinoplasty procedures were performed with the closed technique by minimally invasive techniques incorporating Serdev sutures and Serdev techniques for tip rotation and refinement, narrowing of the alar base, asymetry and irregularity of the nasal dorsum ${ }^{[4,5,6,7]}$, (Picture $1)$. 


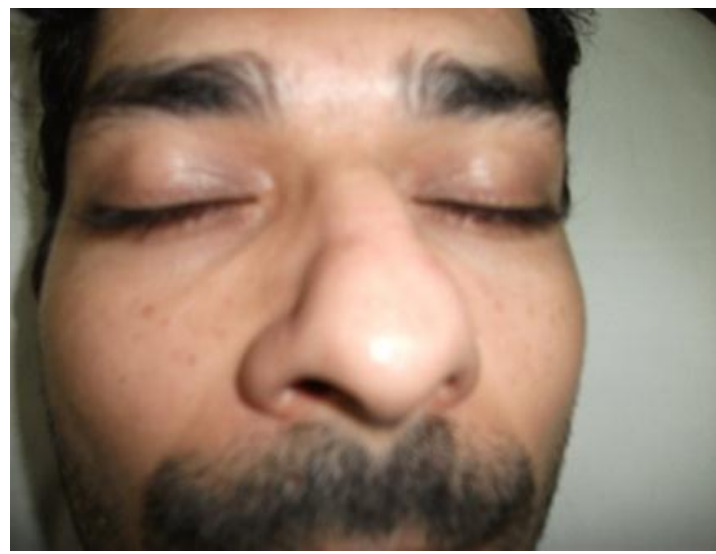

Picture 1a: Pre Op

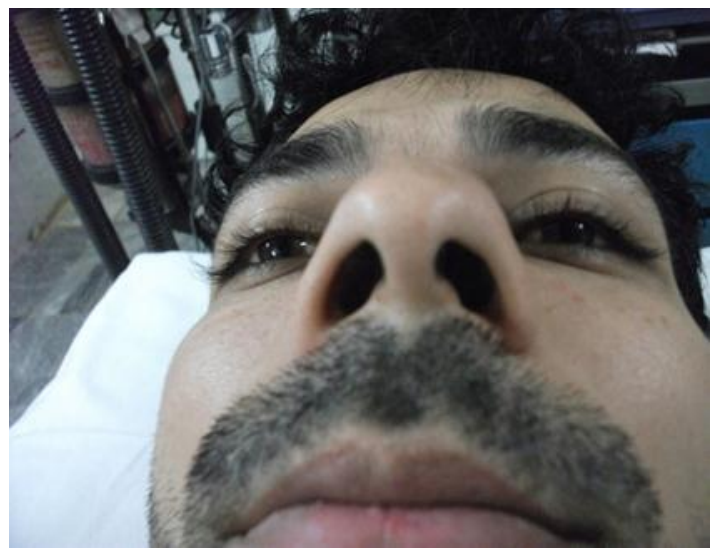

Picture 1c: Pre Op

\section{Material and Methods}

This is a prospective cross sectional observational study of 3 years from July 2014 to July 2017. Nine (15.79\%) patients underwent combined beautification rhinoplasty with intranasal surgery with ENT surgeon out of total 57 patients (chart 1). Postoperatively patients were assessed at one week, three months and six months. The informed consent was obtained for pre operative and post operative pictures from all the patients.

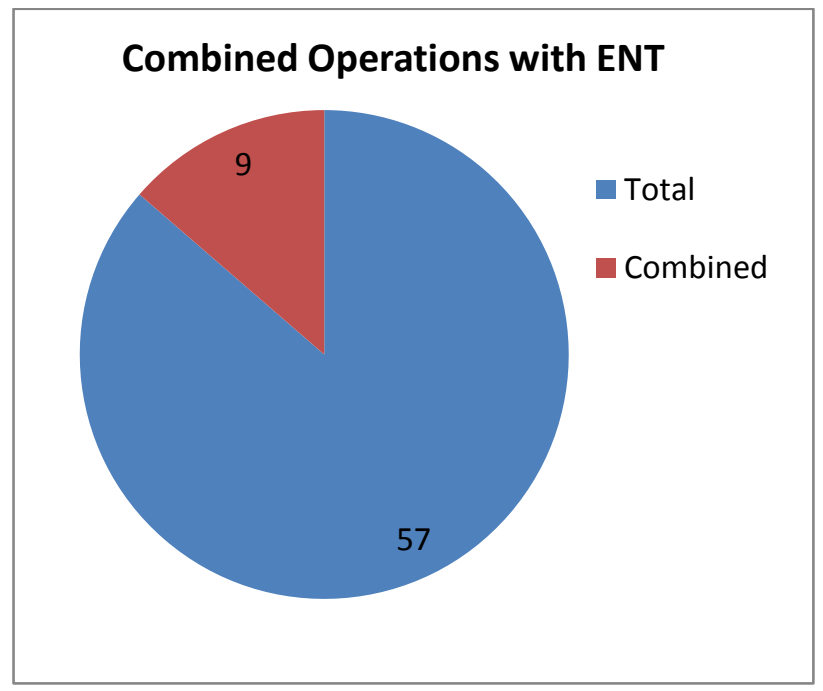

Chart 1: Combined procedures with ENT

There were $38(66.67 \%)$ female and $19(33.33 \%)$ male patients in this study. Age distribution was from 18 years to 66 years, mean age 33 years $\mathrm{SD} \pm 11.56$.

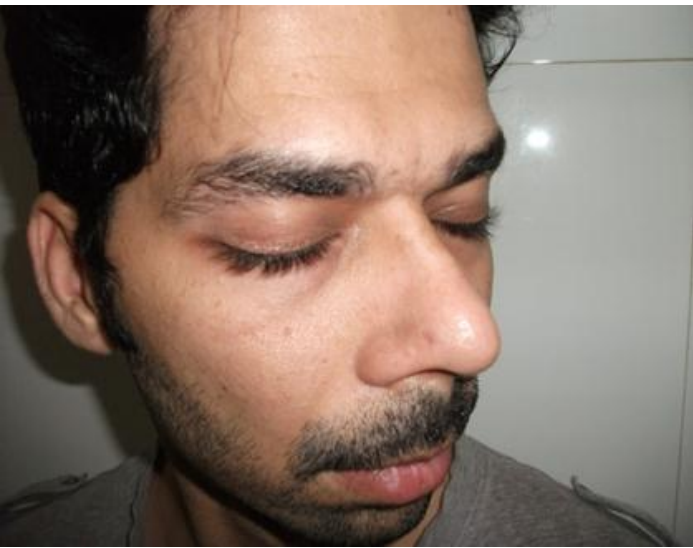

Picture 1b: Post Op

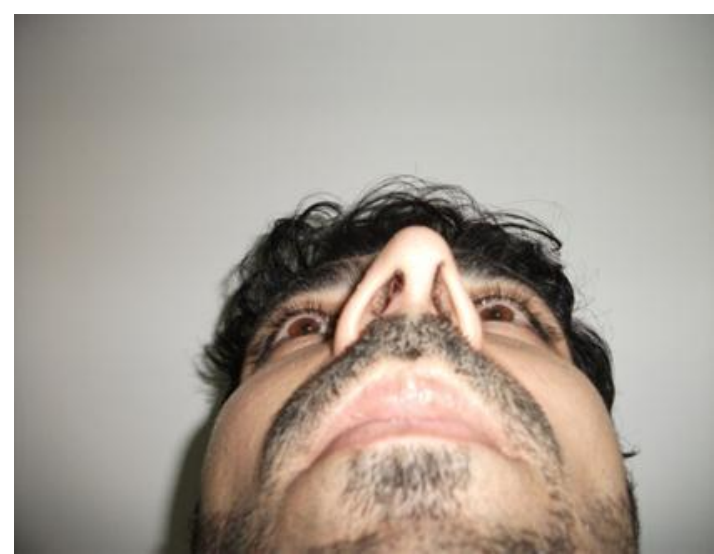

Picture 1d: Post Op

\section{Results}

No complication was reported with the advance minimal invasive techniques for beautification rhinoplasty at 3 months and 6 months follow up and $80-100 \%$ satisfaction level was obtained by using visual analogue scoring system (chart 2).

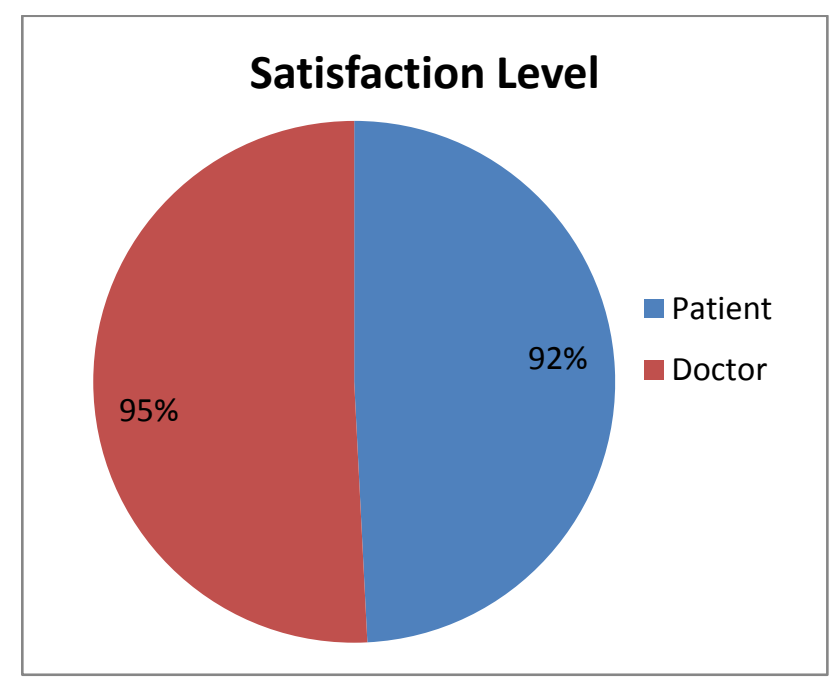

Chart 2: Satisfaction level

\section{Discussion}

Most of the surgeon use open rhinoplasty technique as it provide full exposure of the underlying nasal framework because it provide accurate diagnosis of the intranasal cause of obstruction or cosmetic deformity. Historically, open rhinoplasty is recommended for posttraumatic deformities, secondary rhinoplasty or complex tip modification $^{[7,8]}$. 
For alteration of nasal tip projection, various suture techniques are described or placement of columellar strut with open rhinoplasty technique. A study performed on fresh cadavers head to evaluate the open versus close nasal tip rhinoplasty showed significant loss of tip support as compared to close rhinoplasty ${ }^{[4,5,6,7,8,9,32]}$.

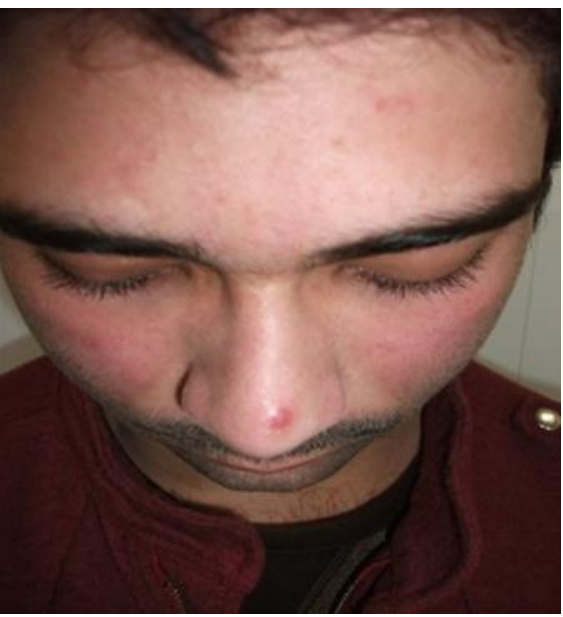

Picture 2a: Tip refinement (Pre Op)

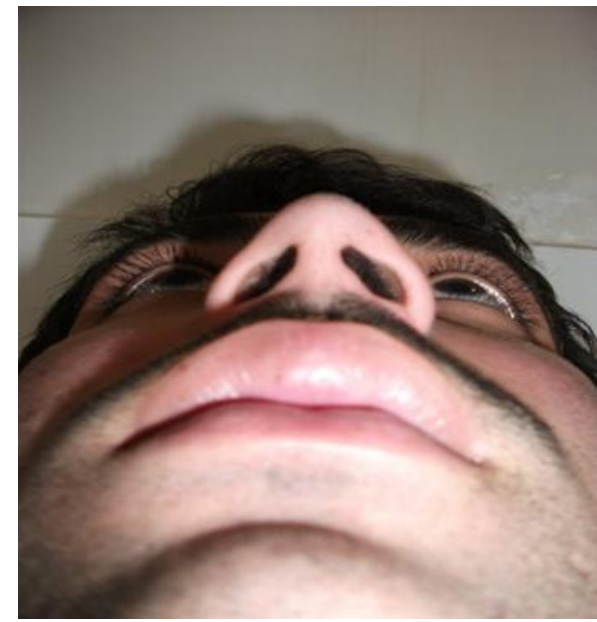

Picture 2c: Tip refinement (Pre Op)

There are various techniques to perform nasal osteotomies medial, transverse, most commonly lateral or combination of osteotomies. Most of the time, osteotomies are performed for narrowing the bony base of the nose and/or to close the open roof deformity after dorsal hump reduction. To achieve the desired results, traditionally the lateral osteotomies performed low-to-high, low-to-low and double level. Furtherance these techniques may be executed by external perforated method and the internal continuous method. The study by Rod Rohrich confirms the superiority of external perforated lateral osteotomy as compared to the internal continuous technique on nineteen fresh cadaver heads in 1997, later revised in $2002^{[8,29,30]}$. The most common complication of lateral osteotomy is the 'step or rocker' deformity. The digital fracture avoid this complication in primary as well as in secondary rhinoplasty. This is simple, atraumatic, saves time and safe technique avoiding external scar, permits the creation of precise pocket for exact fitting of the graft material, healing is better by maintaining vascular bridges produce minimal postoperative edema, bruising and bleeding, less operating time resulting in fast patient recovery ${ }^{[12,13,14,31]}$.

Like any other surgical procedure, rhinoplasty is not without complication such as haematoma, scarring, infection, bruising \& swelling, numbness / sensation changes, vision disturbance, anesthetic risk, asymmetry, lumps, bumps etc. The most common
In my experience, serdev suture technique provide scarless transcutaneous or transmucosal close rhinoplasty technique. It provide highly satisfactory results for tip refinement and alar base narrowing ${ }^{[9,10,11]}$ (Picture 2).

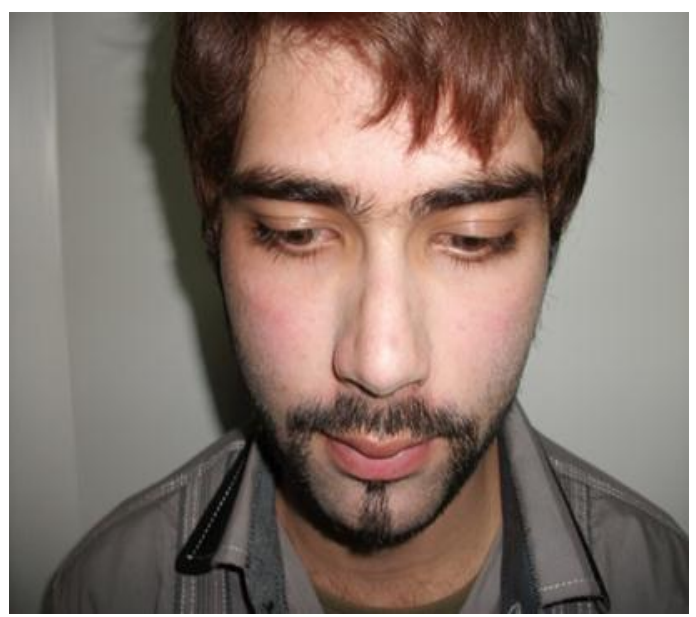

Picture 2b: Tip refinement (Post Op)

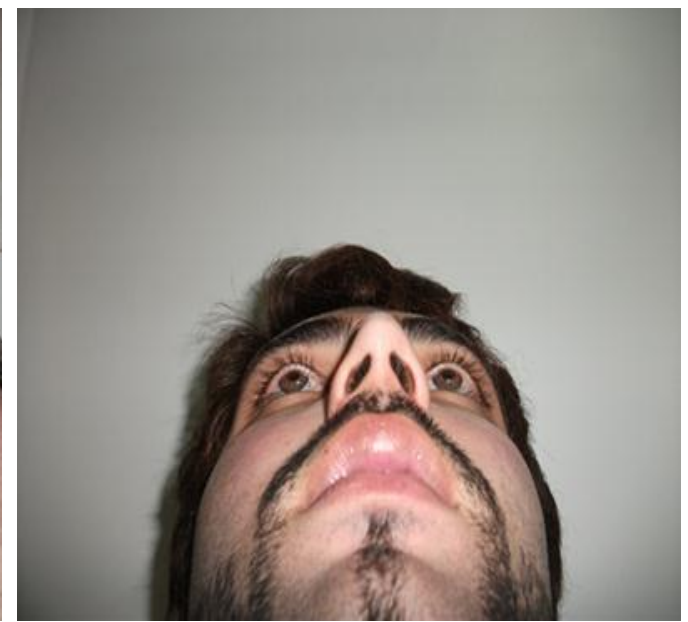

Picture 2d: Tip refinement (Post Op)

complication reported is breathing difficulty or blocked nose ${ }^{[15,16,17,18,19,20,21,22]}$. The most dreadfull complication after rhinoplasty is the blindness ${ }^{[23,24,25,26,27]}$. However, some of the complication may be as a result of mistake in the preoperative assessment or applying inadequate technique ${ }^{[28]}$.

The most common combined intranasal procedures performed by ENT surgeon with the cosmetic rhinoplasty were correction of deflected nasal septum, turbinectomy and polypectomy. My choice of the patients with severe functional problems of the nose having breathing difficulty due to previous surgery or traumatic nasal deformity should have intranasal correction of the deformity to improve breathing prior to cosmetic rhinoplasty. For minor intranasal defects of nasal septum, turbinate hypertrophy, intranasal polyps may have cosmetic rhinoplasty combined with intranasal surgery.

During combined procedure, I let the ENT surgeon to perform turbinectomy, polypectomy before starting cosmetic rhinoplasty procedure. For nasal septal correction, I start making incision usually by total retrocolumellar incision. For nasal tip rotation, $\mathrm{T}$ excision is performed by prolongation of retrocolumellar incision into intercartilagenous incision. The enbloc $\mathrm{T}$ excision is performed with a blunt tip scissor keeping the dorsal skin intact (Figure 1). 

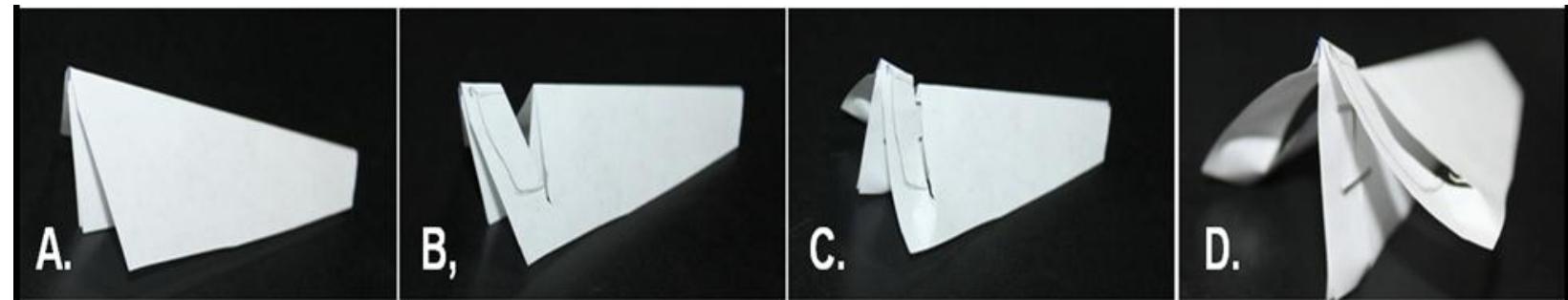

Figure 1: T excision for nasal tip rotation

The beauty triangle is maintained by rotating the nasal tip at the level of the cheekbones. The same incision used for $\mathrm{T}$ excision provide access for dorsal nasal hump removal or any other additional procedure.

In our experience, we have not encountered post operative complication either short term or long term, the combined surgery have definite advantage of having two team approach in a single surgery, less exposure to anesthesia, no post operative complication with high satisfaction level.

\section{Conclusion}

By using advance minimal invasive technique provide predictable results with least or no complication for close rhinoplasty. It provide nearly normal "nonoperated appearance" after atraumatic mini-invasive surgery.

\section{Conflict of Interest}

None

\section{Funding}

None

\section{Ethical Approval}

Obtained

\section{Informed Consent}

Informed consent was obtained from all individual participants included in the study.

\section{References}

[1] Gonzalez Ulloa M, et al. [Skin thickness. Report of our microscopic studyof the total surface of the face and body]. Dia Med. 1961; 33:1880-1896.

[2] Gorney M. Patient selection in rhinoplasty: patient selection. In: Daniel RK, ed. Aesthetic Plastic Surgery: Rhinoplasty. Boston: Little, Brown; 1993.

[3] Gunter JP, Hackney FL. Clinical assessment and facial analysis. In: Gunter JP, Rohrich RJ, Adams WP Jr, eds. Dallas Rhinoplasty: Nasal Surgery by the Masters. St. Louis: Quality Medical Publishing; 2002: 53.

[4] Serdev N P; Closed rhinoplasty Serdev techniques; The PMFA Journal, 2018, Vol 5 No 2.

[5] Serdev N P; Rhinoplasty. Serdev mini-invasive techniques. T-Excision for Nasal Tip Rotation. European Journal of Aesthetic Medicine \& Dermatology. 2016, Vol. 6 Issue 1, p64-74. 11.
[6] Serdev NP: Serdev Techniques in Rhinoplasty. Voenno Izdatelstvo: Sofia, Bulgaria; 2016.

[7] Serdev N P: T-Excision for Nasal Tip Rotation. In: Miniinvasive Techniques in Rhinoplasty. ed. Serdev NP. InTech; 2006:3-13.

[8] Grabb and Smith's Plastic Surgery, Sixth Edition by Charles H. Thorne, 2007 by Lippincott Williams \& Wilkins, chapter 51, p 525.

[9] Serdev N P: Columella Sliding for Nasal Tip Projection Using Septocolumellar Transmucosal Mattress Sutures. In: Miniinvasive Techniques in Rhinoplasty. ed. Serdev NP. InTech; 2006:21-8.

[10] Rohrich RJ, Adams WP Jr, Deuber MA. Graduated approach to tip refinement and projection. In: Gunter JP, Rohrich RJ, Adams WP Jr, eds. Dallas Rhinoplasty: Nasal Surgery by the Masters. St. Louis: Quality Medical Publishing; 2002: 333.

[11] Serdev N P: Transcutaneous and Transmucosal Serdev Sutures ${ }^{\circledR}$ for Nasal Tip Refinement, Alar Base Narrowing, and Other Corrections. In: Miniinvasive Techniques in Rhinoplasty. ed. Serdev NP. InTech; 2006:37-56.

[12] Harshbarger RJ, Sullivan PK. Lateral nasal osteotomies: implications of bony thickness on fracture patterns. Ann Plast Surg. 1999;42(4):365-370; discussion 370-371.

[13] Sullivan PK, Harshbarger RJ, Oneal RM: Nasal Osteotomies. In Gunter JP, Rohrich RJ, Adams WP Jr, eds. Dallas Rhinoplasty: Nasal Surgery by the Masters. St. Louis: Quality Medical Publishing; 2002:595.

[14] Serdev N P: Digital Fracture Versus Lateral Osteotomy. In: Miniinvasive Techniques in Rhinoplasty. ed. Serdev NP. InTech; 2006:29-32.

[15] Rettinger G: Risks and complications in rhinoplasty; GMS Curr Top Otorhinolaryngol Head Neck Surg. 2007; 6. Doc08. Epub 2008 Mar 14.

[16] Bracaglia R, Fortunato R, Gentileschi S. Secondary rhinoplasty. Aesthetic Plast Surg. 2005; 29(4):230-239.

[17] Foda HM. Rhinoplasty for the multiply revised nose. Am J Otolaryngol. 2005; 26(1):28-34.

[18] Cheney ML, Blair PA. Blindness as a complication of rhinoplasty. Arch Otolaryngol Head Neck Surg. 1987; 113(7):768-769.

[19] Jaison SG, Bhatty SM, Chopra SK, Satija V. Orbital apex syndrome: a rare complication of septorhinoplasty. Indian J Ophthalmol. 1994; 42(4):213-214.

[20] Kubota T, Hirose H. Permanent loss of vision following cosmetic rhinoplastic surgery. Jpn J Ophthalmol. 2005; 49(6):535-536.

[21] Wind J. Blindness as a complication of rhinoplasty. Arch Otolaryngol Head Neck Surg. 1988; 114(5):581.

[22] Rettinger G, Christ P, Meythaler FH. Blindness caused by central artery occlusion following nasal septum correction. HNO. 1990; 38:105-109. 
[23] Cheney ML, Blair PA. Blindness as a complication of rhinoplasty. Arch Otolaryngol Head Neck Surg. 1987; 113(7):768-769.

[24] Jaison SG, Bhatty SM, Chopra SK, Satija V. Orbital apex syndrome: a rare complication of septorhinoplasty. Indian J Ophthalmol. 1994; 42(4):213-214.

[25] Kubota T, Hirose H. Permanent loss of vision following cosmetic rhinoplastic surgery. Jpn J Ophthalmol. 2005; 49(6):535-536. Kubota T, Hirose H. Permanent loss of vision following cosmetic rhinoplastic surgery. Jpn J Ophthalmol. 2005; 49(6):535-536.

[26] Wind J. Blindness as a complication of rhinoplasty. Arch Otolaryngol Head Neck Surg. 1988; 114(5):581.

[27] Rettinger G, Christ P, Meythaler FH. Blindness caused by central artery occlusion following nasal septum correction. HNO. 1990; 38:105-109.

[28] Rettinger G. Complication or mistake. Fac Plast Surg. 1997; 13(1).
[29] Rohrich, Rod; Minoli, John; Adams, William; Hollier, Larry; the Lateral Nasal Osteotomy in Rhinoplasty: An Anatomic Endoscopic Comparison of the External versus the Internal Approach; Plastic and Reconstructive Surgery: 1997, Vol 99, Issue 5, PP 1309-1312.

[30] Rohrich R J, Jeffrey E. Janis, William P. Adams, and Jeffery K. Krueger; An Update on the Lateral Nasal Osteotomy in Rhinoplasty: An Anatomic Endoscopic Comparison of the External versus the Internal Approach; Revised for publication 2002; Plast. Reconstr. Surg. 99: 1309, 1997.

[31] Cafferty A, Becker DG; Open and Closed Rhinoplasty, Clin Plast Surg. 2016 Jan;43(1):17-27. doi: 10.1016/j.cps.2015.09.002

[32] Adams WP Jr , Rohrich RJ, Hollier LH, Minoli J, Thornton LK, Gyimesi I; Anatomic basis and clinical implications for nasal tip support in open versus closed rhinoplasty; Plastic and Reconstructive Surgery [01 Jan 1999, 103(1):255-61; discussion 262-4] 